\title{
The Salinity Effects on Germination and Early Seedling Growth of Bean Plants (Bean Phaseolus)
}

\section{Advances in Earth and Environmental Science}

Research Article

\begin{abstract}
Firew Admasu Hailu* and Ahmedin Jeylan
\end{abstract}
Dilla University, College of Natural and Computational Sciences, Department of Biology, Dilla, Ethiopia

\author{
*Correspondence author \\ Firew Admasu Hailu \\ Dilla University \\ College of Natural and Computational Sciences \\ Department of Biology \\ Dilla \\ Ethiopia
}

Submitted : 4 Sept 2020 ; Published : 27 Nov 2020

\begin{abstract}
The study was conducted at Dilla University, in the laboratory of Biological sciences to see the effects of salinity on germination and early seedling.

Background: It is estimated that the world 20\% of farming land and 50\% of cropland is salt stressed and salinity decreases the germination of seed, retards the growth of plant and so it reduces the yield of crop.

Objective: The major objective of this research was to evaluate the effects of salinity on the germination and early seedling growth of bean plants. Specifically, to investigate salt tolerant efficiency, salt effect on seed germination and its rate and growth of bean plant at different concentration of $\mathrm{NaCl}$.
\end{abstract}

Methodology: The experiment required 21 groups, of which 20 of them were experimental with different salt concentrations ranging from 0.05M to $1.00 \mathrm{M}$ with $0.05 \mathrm{M}$ difference and one control group. Each group contain three bean seed measuring its weight using electronic balance machine, sterilized with $70 \%$ Alcohol solution for 15 seconds, rinsed with distilled water, placed in separate Petri dish using a forceps, 50ml of solution were added to each Petri dish with different concentration, all Petri dishes were covered with lids and kept into incubator at room temperature for 17 days, germinated seed were counted, seedlings root and shoot length were measured using a ruler. Finally, the Bean was transferred to non-saline condition, weight of germinated Bean were measured to compare with their normal weight and to determine the effects of salt on seed weight, which was conducted in triplicates. All necessary data was taken, analyzed and interpreted in the form of percentage, graph, tables and figures.

Result: When the concentration of salt increased the Bean plant is extremely affected, germination rate decreased and the terminal weights of seed were become lower than the initial weight due to the absorption of water by seed.

Conclusions: The rate of germination decrease when the salt concentration increased and late growth of length of root and shoot when the salt dosage is highest and also the weights of seed reduced as concentration of salt is raised. Generally, as the concentration of salt is increased the Bean plant is extremely affected.

Keywords/Phrase: Early Seedling, Salinity Effect, Salt Concentration, Seed Germination.

\section{Introduction}

In the world, about 95 million hectares plant productivity is affecting by limiting factor known as soil salinity [1]. The growth of crop plants are exposed to different environmental stresses such as salinity and drought limit their growth and productivity and also due to these from world cultivated lands estimated more than $20 \%$ contain high salt levels to cause salt stress on crop plants [2][3]. Seedlings has vulnerable life cycle of seed plants and their germination determines when seedling growth begins on the soil salt concentration [4]. The United Nations Environment Program (UNEP) salt stressed estimates that $20 \%$ of the agricultural land and $50 \%$ of the cropland in the world and also salinity imposes environmental problems that affect grassland and accessibility of animal feed in dry and semi-arid regions [5] [6]. Salt pressure adversely affected the growth and productivity of plant during all developmental stages and salinity decreases seed germination, retards plant development and reduces crop yield [7]. Maximum germination of seeds of most plant species reach in distilled water and sensitive to elevated salinity at the germination and seedling phases of development [8].

In many plant species, seed germination and early seedling growth are the most salinity sensitive stages to attain maximum germination without $\mathrm{NaCl}$ and salinity elevated 
at the germination and early establishment phases [9]. Many physiological aspects of plant shoot growth and dry matter are reduced by salinity and it also affect seeds of germination by creating osmotic potential which prevent water uptake, or by toxic effects of ions on embryo viability [10] [11]. Osmotic potential reduction in salt stressed plant is a result of inorganic ion $(\mathrm{Na}+, \mathrm{Cl}-$ and $\mathrm{K}+)$ and accumulations of complete organic solute [12]. Increased salinity causes reduction in germination percentage, rate, both length and weights of root and shoots [13]. Growth of shoot reduced by salinity due to inhibitory effect of salt on cell division and growing point [14]. Soil salinity is one of the major constraints in beans production due to chloride and sulfate accumulation, some have a very high germination capacity and seedling growth on saline soil, while others have well germinate, but with a very poor seedling growth in saline soil [15].

In crop plants, germination and seedling characteristics are the most feasible criteria used for selecting salt tolerance and the germination percentage, rate, and seedling growth are important growth parameters [16] [17]. Bean Phaseolus species is salt sensitive and its yield highly reduced by effects of salinity wide ranging from germination to stages of vegetative, fruiting, and padding; and salinity tolerance of Phaseolus species differs from one genotype to another [18]. Germination is the first stage of a plant's life cycle for establishment of a crop, oxidization takes place within the seed to breaks down storage proteins to obtain energy and amino acids necessary for the development of plant [19]. The legume family is the third largest of flowering plants [20]. Economically, legumes represent the second most important crop plants after Phocaea family, about $27 \%$ of the world's production of crops [21].

In Africa, Ethiopia is the second well known of producer of food legumes next to Egypt [22]. However, about 10,608 half of the total land of Ethiopia's is affected by salinity and may reduce the yield in both arid and semi-arid regions [23]. Moreover, saline in semi-arid parts of irrigated lands are increase and so rotating to new scenarios of food production for the fast growing population is important [24]. Beans are an important source of protein in East and Great Lake of Africa, which play an vital role in human nutrition, providing as much as $45 \%$ of the total protein consumed [25]. In addition, it plays an important role in soil fertility, particularly in arid regions [26]. Therefore, in the countries like Ethiopia where legume plants are mainly grown for human food consumption for the rapid population growing, focus should be given on the development of salt tolerant crops species and cultivate is important to reach their food security. In addition, there are a number of problems caused by salinity on plant germination, growth and productivity. In order to improve agricultural productivity, improving salt tolerance of crop plants has great potential. Agriculture is backbone of the country's economy but the sector is highly influenced by natural, social and human induced problem. In Ethiopia Bean Phaseolus species is the main cash crops, grown by small farmers and used as a major food legume in many parts of the country. Thus why, such kind of problems initiate the researchers to undertake this study on the objective of investigating salinity effect on both germination and early seedling of Bean plants, because of identification of salt tolerant species have huge value for agriculture. Specifically, to investigate salt tolerant efficiency, to identify the effect of salt on the germination and to determine rate of germination and growth of bean plants at different concentration of $\mathrm{NaCl}$.

\section{Materials and Methods}

Description of Study Area: The study was conducted in Dilla University main campus, at the laboratory of biological sciences department, located in southern nation, nationalities and people of regional state (SNNPR), at about $360 \mathrm{~km}$ to south from Addis Ababa, Ethiopia.

Materials used for the study: The following materials / chemicals and instruments was used for this research work, these are; Petri dish $(9.5 \mathrm{~cm}$ diameter), Sodium chloride $(\mathrm{NaCl})$, Bean seed, $70 \%$ Alcohol, Distilled water, Balance machine, Laminar air flow.

Treatment and solution preparation: Before the beginning of the experiment, the solutions was prepared from sodium chloride $(\mathrm{NaCl})$ and distilled water. There are 20 experimental groups with different salt concentrations and one control group without any addition of salt. The experimental groups are labeled as $0.05 \mathrm{M}, 0.10 \mathrm{M}, 0.15 \mathrm{M}, 0.20 \mathrm{M}, 0.25 \mathrm{M}, 030 \mathrm{M}$, $0.35 \mathrm{M}, 0.40 \mathrm{M}, 0.45 \mathrm{M}, 0.50 \mathrm{M}, 0.55 \mathrm{M}, 0.60 \mathrm{M}, 0.65 \mathrm{M}$, $0.70 \mathrm{M}, 0.75 \mathrm{M}, 0.80 \mathrm{M}, 0.85 \mathrm{M}, 0.90 \mathrm{M}, 0.95 \mathrm{M}, 1.00 \mathrm{M}$ and the controlled group is $0 \mathrm{M}$. The solution were left for 6 hours until completely dissolved. The concentrations of the solutions were prepared by using molar conversion method as follows.

$$
M=N / V .
$$

Where, $\mathrm{M}$ is molecular mass,

$\mathrm{N}$ is number of mole, and

$\mathrm{V}$ is volume.

$\mathrm{N}=$ molar mass/ given mass (mass of $\mathrm{NaCl}$ )

Molar concentration $=$ mass of $\mathrm{NaCl} /$ molecular mass $\mathrm{x}$ Volume .

Mass of $\mathrm{NaCl}=$ Molar concentration $\mathrm{x}$ molecular mass $\mathrm{x}$ Volume.

The salt $(\mathrm{NaCl})$ was added to $50 \mathrm{ml}$ of distilled water depending on the needed concentration. The salt concentration was prepared as follows (Table 1).

\begin{tabular}{|l|l|l|l|}
\hline No & $\begin{array}{l}\text { Concentration } \\
(\mathrm{M})\end{array}$ & $\begin{array}{l}\text { Amount of } \\
\mathrm{NaCl} \text { added }(\mathrm{g})\end{array}$ & $\begin{array}{l}\text { Amount Distilled } \\
\text { water }(\mathrm{ml})\end{array}$ \\
\hline 1 & 0.00 & 0 & 50 \\
\hline 2 & 0.05 & 0.15 & 50 \\
\hline 3 & 0.10 & 0.29 & 50 \\
\hline 4 & 0.15 & 0.44 & 50 \\
\hline 5 & 0.20 & 0.58 & 50 \\
\hline 6 & 0.25 & 0.73 & 50 \\
\hline 7 & 0.30 & 0.87 & 50 \\
\hline
\end{tabular}




\begin{tabular}{|l|l|l|l|}
\hline 8 & 0.35 & 1.02 & 50 \\
\hline 9 & 0.40 & 1.27 & 50 \\
\hline 10 & 0.45 & 1.31 & 50 \\
\hline 11 & 0.50 & 1.46 & 50 \\
\hline 12 & 0.55 & 1.60 & 50 \\
\hline 13 & 0.60 & 1.75 & 50 \\
\hline 14 & 0.65 & 1.90 & 50 \\
\hline 15 & 0.70 & 2.04 & 50 \\
\hline 16 & 0.75 & 2.18 & 50 \\
\hline 17 & 0.80 & 2.34 & 50 \\
\hline 18 & 0.85 & 2.50 & 50 \\
\hline 19 & 0.90 & 2.65 & 50 \\
\hline 20 & 0.95 & 2.77 & 50 \\
\hline 21 & 1.00 & 2.92 & 50 \\
\hline
\end{tabular}

graph and tables. The parameter measured was included percent germination, length of shoot and percentage of shoot length, length of root and percentage of root length in each concentration and the weight of germinated Bean.

\section{Results and Discussion}

Rresults: The result of this experimental study indicates that, as the concentration of salt is increased the Bean plant is extremely affected as indicated in figure 1 under.

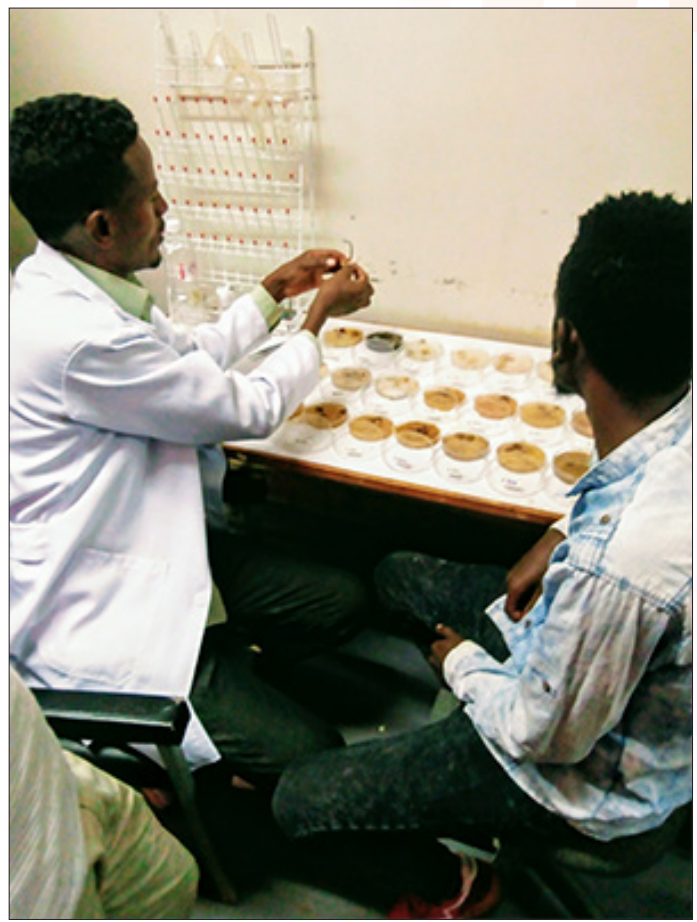

All the required Petri dishes was prepared as germination chambers and labeled based on salt concentrations, then disinfected with $70 \%$ alcohol and UV to make free from microorganisms.

Experimental Design: The Bean seeds and Salt $(\mathrm{NaCl})$ were bought from the Dilla town (Market) to the laboratory and sieved to eliminate broken, small and defected seeds. The normal sixty three (63) seeds were taken and randomly divided in to 21 group (each group has three seed). Each seed group's weight were measured using electronic balance machine, and then the seeds were sterilized with $70 \%$ Alcohol solution for 15 seconds and rinsed with distilled water. Each of experimental seed groups were placed in a Petri dish $(9.5 \mathrm{~cm}$ diameter) using a forceps (three in one), then, $50 \mathrm{ml}$ of prepared salt concentration was added to it by following the amount of labeled concentration and $50 \mathrm{ml}$ of distilled water is added in to the control group and finally, all of them covered with lids and kept into incubator at room temperature $\left(24 \pm 2{ }^{\circ} \mathrm{C}\right)$ and the experiment lasted at 17 days. Germination count was made on $17^{\text {th }}$ day and the germinated seeds identified based on the appeared and visible shoot and root. Then, length of both root and shoot of seedling were measured using a ruler. Finally, the Bean was transferred from saline condition (Petri dish) to nonsaline condition in order to measure the weight of germinated Bean to compare with their normal weight and to determine the effects of salt on seed weight. The experiment was conducted in triplicate to increase the validity of the result.

Data collection and Analysis: All necessary data including measuring the length of shoot and root of beans in the different salt concentration and the weights of seed before and after germination were recorded. Mean and percentage of statistical data analysis was performed to identify the differences between control growth and experimental growth and within the experimental group each other. The obtained data were analyzed and interpreted in the form of percentage,

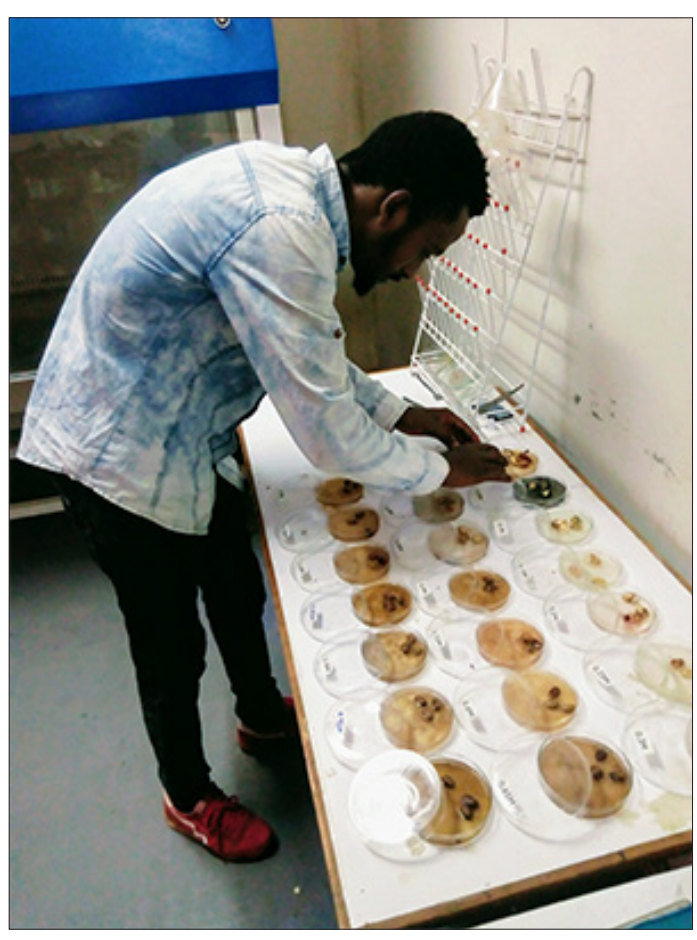




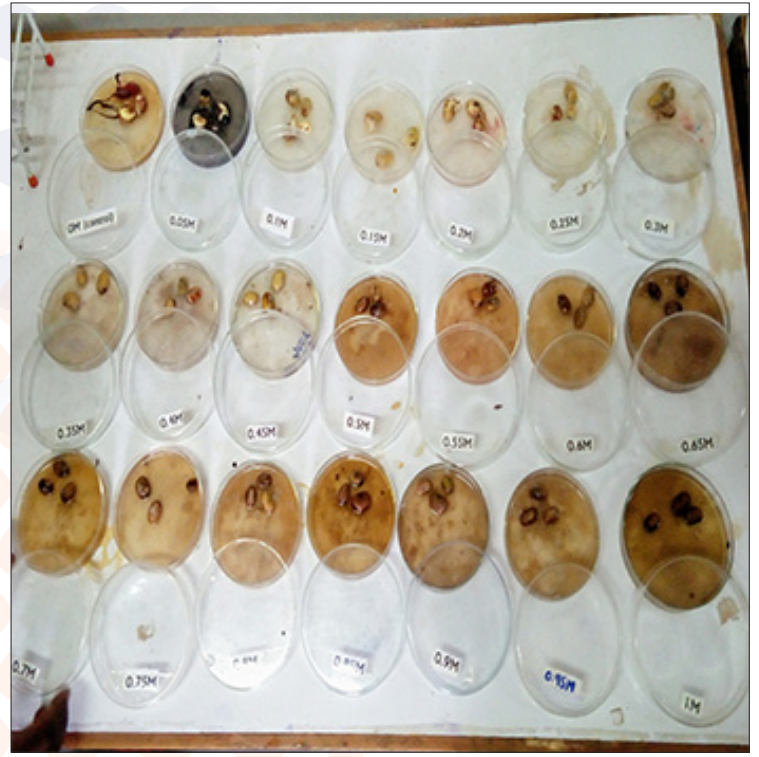

Based on the result of this experimental observation as indicated above in figure $1, \mathrm{Up}$ to $0.20 \mathrm{M}$ there is certain amount of observable seed germination. However, above $0.20 \mathrm{M}$ there is no any observable seed germination. As the higher concentration of salt is limited in water absorption, and slower in germination rate. In the salt concentration from $0.25 \mathrm{M}$ $0.35 \mathrm{M}$ the seed coat broken was seen for starting germination but become unseen as salt concentration were increased and there's no observable shoot and root germination. There was significant differences observed between treatments for germination rate and which means that the germination rate decrease when the salt concentration is increased and late for the highest salt dosage of the study seeds.

Effects of salinity on the growth of root and length of shoot seed: Both root and shoot length was measured by using ruler after 17 days exposure and the maximum length of the shoot result were recorded on the control group, which is $58 \mathrm{~mm}$ and it was gradually decreased to $39,19,10$ and $9 \mathrm{~mm}$ in the salt concentrations increases from $0.05,0.10,0.15$ and 0.20 $\mathrm{M}$, respectively. Similarly, the length of the root reduced in all the treated Bean seeds when compared to the control and $35 \mathrm{~mm}$ was recorded in the control and gradually reduced as the concentration of the salt is increased and the recorded results were 12, 10, 6 and $0 \mathrm{~mm}$, respectively. The maximum and minimum results of all the study are summarized in Table 2 and figure 2 bellow.

\begin{tabular}{|l|l|l|l|l|l|}
\hline \multirow{2}{*}{ No } & \multirow{2}{*}{\begin{tabular}{l} 
Concentration \\
\cline { 3 - 6 }
\end{tabular}} & \multicolumn{2}{|l|}{$\begin{array}{l}\text { Length of Root } \\
(\mathrm{mm})\end{array}$} & \multicolumn{2}{l|}{$\begin{array}{l}\text { Length of Shoot } \\
(\mathrm{mm})\end{array}$} \\
\cline { 3 - 6 } & Maxim & Minim & Maxim & Minim \\
\hline 1 & $0($ Control $)$ & 35 & 18 & 58 & 21 \\
\hline 2 & 0.05 & 12 & 2 & 39 & 11 \\
\hline 3 & 0.10 & 10 & 2 & 19 & 17 \\
\hline 4 & 0.15 & 6 & 0 & 10 & 6 \\
\hline 5 & 0.20 & 0 & 0 & 9 & 6 \\
\hline
\end{tabular}

Table 2: The effect of salinity on the root and shoot length.

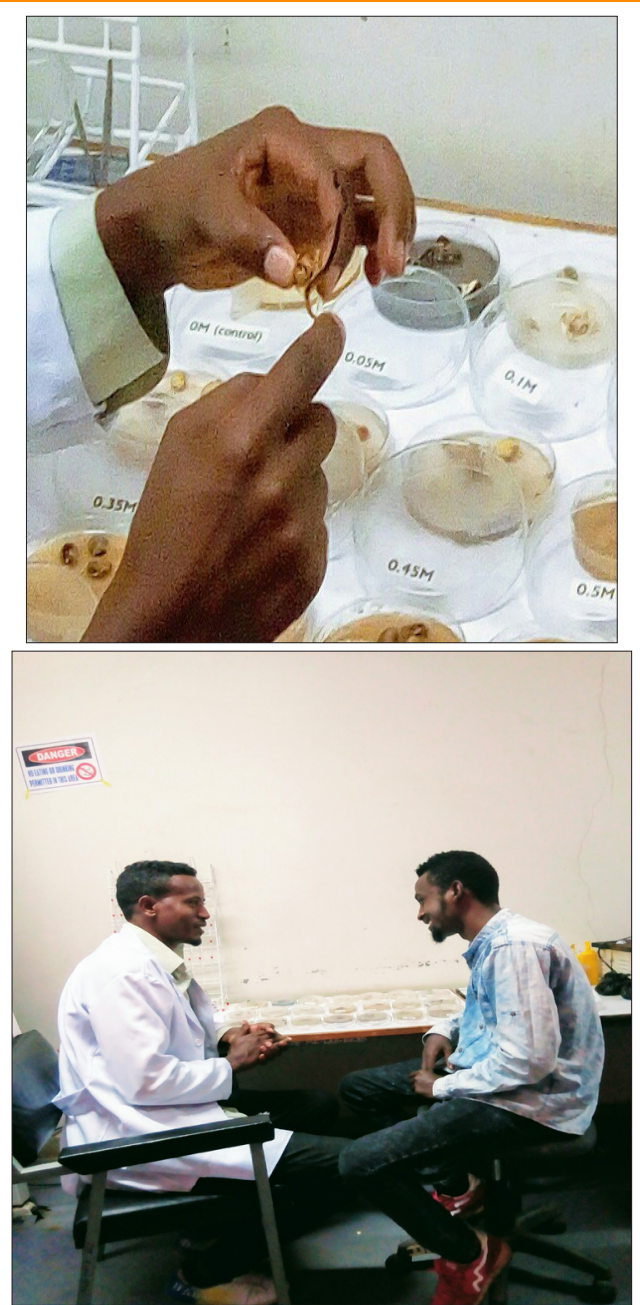

The percentage growth of shoot length was also reduced from $100 \%$ in the control to $67.24,32.75,17.24$ and $15.52 \%$ in the salt concentrations of $0.05,0.10,0.15$ and $0.20 \mathrm{M}$, respectively and summarized as follows on chart 1 bellow.

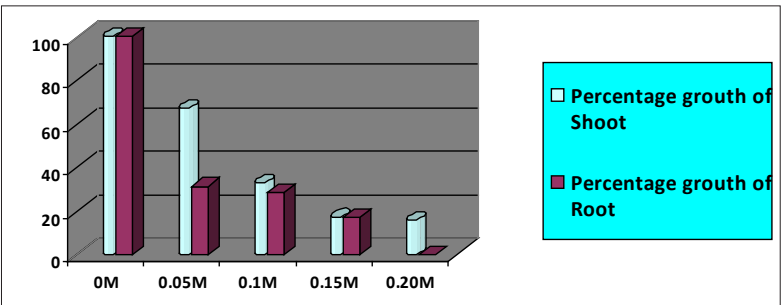

Chart 1: The effects of different salt concentration on the growth of root length and shoot length by percentage.

The effects of salinity on the weight of seed:- The weight of seed was recorded by Mean (measuring three seeds together that were added in one Petri dish, then divided for three). The terminal weights of seed were become lower than the initial weight as the concentration of salt is increased. This is due to seed inhibition of water absorption from their surrounding by salt and salt absorption of moisture from seed. The salinity effects on the weight of seed of 20 experimental and a control group are summarized as follows in Table 3. 


\begin{tabular}{|l|l|l|l|l|}
\hline No & $\begin{array}{l}\text { Concentration } \\
(\mathrm{M})\end{array}$ & $\begin{array}{l}\text { Initial } \\
\text { weight of } \\
\text { seed }(\mathrm{g})\end{array}$ & $\begin{array}{l}\text { Terminal } \\
\text { weights } \\
\text { of seed } \\
\text { (g) }\end{array}$ & $\begin{array}{l}\text { The } \\
\text { difference } \\
\text { (effects) }\end{array}$ \\
\hline 1 & 0 (control) & 1.84 & 2.38 & +0.54 \\
\hline 2 & 0.05 & 1.66 & 2.19 & +0.53 \\
\hline 3 & 0.10 & 1.63 & 1.75 & +0.12 \\
\hline 4 & 0.15 & 1.67 & 1.64 & -0.03 \\
\hline 5 & 0.20 & 1.84 & 1.61 & -0.23 \\
\hline 6 & 0.25 & 1.80 & 1.31 & -0.49 \\
\hline 7 & 0.30 & 1.78 & 1.29 & -0.49 \\
\hline 8 & 0.35 & 1.87 & 1.20 & -0.67 \\
\hline 9 & 0.40 & 1.78 & 1.15 & -0.63 \\
\hline 10 & 0.45 & 1.88 & 1.10 & -0.78 \\
\hline 11 & 0.50 & 1.76 & 1.14 & -0.62 \\
\hline 12 & 0.55 & 1.80 & 1.17 & -0.63 \\
\hline 13 & 0.60 & 1.77 & 1.15 & -0.62 \\
\hline 14 & 0.65 & 1.79 & 1.13 & -0.66 \\
\hline 15 & 0.70 & 1.79 & 1.14 & -0.65 \\
\hline 16 & 0.75 & 1.78 & 1.16 & -0.62 \\
\hline 17 & 0.80 & 1.76 & 1.10 & -0.66 \\
\hline 18 & 0.85 & 1.82 & 1.17 & -0.68 \\
\hline 19 & 0.90 & 1.85 & 1.23 & -0.62 \\
\hline 20 & 0.95 & 1.88 & 1.20 & -0.68 \\
\hline 21 & 1.00 & 1.80 & 1.14 & -0.66 \\
\hline & Table 3: The effects & & & \\
\hline
\end{tabular}

Table 3: The effects of salinity on the weight of seed

As seen above on the table 3 about different concentration, initial and terminal weight of experimental bean seed of 21 groups with their differences indicate that, the terminal weights of seed was become decreased as salinity increased up to $0.45 \mathrm{M}$. This indicate the effects of salt on the weight of seed. The seed in the salt concentration from control up to $0.45 \mathrm{M}$ the seed coat were broken. This indicate the internal nutrient (material) are still upon starting the germination at low germination rate due to salt effects, and some are discharged out through the broken coat of seeds and this may a reason to loss the weight of seed. In addition, from $0.50 \mathrm{M}-1.00 \mathrm{M}$ the terminal weights of seed are nearly on the stationary as salinity increased, but lower than the original seed weight. The color of seed was changed and become black as concentration of salt is increased, especially above $0.50 \mathrm{M}$ due to accumulation of salt and inhibitory effects of the solution low osmotic potential and also the Bean seed were died as salt concentration is increased.

\section{Discussion}

In many seed plant species, germination and early seedling are the most sensitive to salinity pressure. The maximum germination in the absence of $\mathrm{NaCl}$ and are very sensitive to elevated salinity and early establishment phases [8]. Shoot growth are reduced by salinity [9] This result is similar with the current study, when salt concentration increased, germination of seed reduced, the growth of shoot and root is affected. The result of this study is comparable with both Munns, and Jamil et al., $[13,14]$. Meaning that, increasing salinity concentration can causes decrease in germination percentage and rate, length of both root and shoots and also fresh root and shoots weights due to the inhibitory effect of salt on cell division and enlargement in the growing point $[13,14]$. The current studies showed that, the root and shoot length and also weight of Bean Phaseolus spp, were affected by different salt concentration levels.

The result of the current study also supported by different researchers such as Epstein et al., Ghoulam and Fares, (2001), Munns, and Gulzar et al., [6,7,8]. Salt stress critically affected plant growth and productivity during all developmental stages by decreasing germination rate, retards the development of plant and reduces the yield of crop [6]. Several investigations on most species of seed germination under salinity stress reach maximum germination in distilled water and seedling phases of development [7]. Increased salinity causes a significant reduction in germination percentage, germination rate, and root and shoots length as well as fresh root and shoots weights [13]. Shoot growth was reduced by salinity due to the inhibitory effect of salt on cell division and enlargement in the growing point [14].

\section{Conclusions}

Based on the result of this study, the following conclusions are made. From control up to $0.20 \mathrm{M}$ there is observable seed germination, but the germination rate decrease as salt concentration increased and delayed for the highest salt dosage. The length of root and shoot as well as the weights of seed were reduced as concentration of salt is raised, due to seed inhibition of water absorption by salt and salt absorption of moisture from seed. In high salt concentration $(0.5 \mathrm{M}$ and above) the seed were going to die and the color is changed to black because of ionic toxicity. Generally, as the salt concentration is increased the Bean plant is extremely affected.

\section{Recommendations}

The outcome of the research provided information about tolerance of the Bean Phaseolus species at different salinity levels. Depending on the result of this study, it is recommended that selection of salt concentration is helpful to combat the effects of the salinity condition on Bean. The current studies showed that, the root and shoot length and weight of Bean Phaseolus spp, were affected by different salt concentration levels. Hence, further evaluation of Bean for salinity tolerance both in laboratory and field conditions should be encouraged. The salinity effect under the field condition may not be the same due to the large variations in the environmental conditions. Strategy can be made row crops in salt affected soil or saline water by utilizing the probable reduction in germination and other parameters. The government and agricultural expert wood provide support for farmers either way of administration or supply of salt tolerant crops and promoting of salinity 
management practice. Agricultural office of the country should give awareness for farmers about its direct and indirect effect of salinity. According to this study the tolerance of Bean plants is up $0.20 \mathrm{M}$ salt concentrations. Farmers recommended cultivating Bean plants in low salinity of soil less than $0.20 \mathrm{M}$.

\section{References}

1. Szabolcs I, Pessarakli M (1994) Soils and Salinization. In: Handbook of Plant and Crop Stress, (Ed.). Marcel Dekker, New York, pp: 3-11.

2. Reynolds T (1975) Characterization of osmotic restraints on lettuce from germination. Ann. Bot. 39: 791-796.

3. Loercher L (1974) Persistence of red light induction in lettuce seeds of varying hydration. Plant Physiol. 53: 503506.

4. Flowers T.J, A.R. Yeo (1995) Breeding for salinity resistance in crop plants: Where next? Aust. J. Plant Physiol, 22: 875-884.

5. El-Kharbotly A, O. Mahgoub, A. Al-Subhi, A. Al-Halhali (2003) Indigenous grass species with potential for maintaining rangeland and livestock feeding in Oman. Agricultural, Ecosystems, Environment 95: 623-62.

6. Epstein E, J.D. Norlyn, D.W. Rush, R.W. Kingsbury, D.B. Kelley, G.A. Cunningham, A.F. Wrona (1980) Saline culture of crops: A genetic approach. Science 210: 399 404.

7. Gulzar S, M.A. Khan, L.A. Ungar (2003) Salt tolerance of a coastal salt marsh grass. Common. Soil Sci. Plant Anal., 34: 2595-2605.

8. Khan M.A, I.A. Ungar, A.M. Showalter (2000) Effects of sodium chloride treatments on growth and ion accumulation of the halophyte Haloxylon recurvum. Commun. Soil Sci. Plant Anal., 31: 2763-2774.

9. Rahman M, Soomro U, Zahoor-ul-Hag M, Gul Sh (2008) World J. of Agricultural Sciences 4(3): 398-403.

10. Loercher L (1974) Persistence of red light induction in lettuce seeds of varying hydration. Plant Physiol. 53: 503506.

11. Houle GL, Morel L, Reynolds CE, Seigel J (2001) The effect of salinity on different developmental stages of an endemic annual plant, Asterlaurenti anus. Am. J. Bot. 88: 62-67.

12. Hasegawa, Hawada A.M, Hassen (2000) Effect of salinity on germination growth and ionic content of three variety of barley 2:87-98p.

13. Jamil M, Lee B.D, Jung Y.K, Ashraf M, Lee C.S, Rha S.E (2006) Effect of salt $(\mathrm{NaCl})$ stress on germination and early seedling growth of four vegetables species. $J$. Central Eur. Agric. 7(2): 273-282.

14. Munns R (2002) Comparative physiology of salt and water stress. Plant Cell Environ 28: 239-250.

15. Asfaw T, Ghosh K (2000) Micro molecular structure of humic substance. Soil. Sci. 129:266-278.

16. Jamil M, Rha E.S (2004) The effect of salinity $(\mathrm{NaCl})$ on the germination and seedling of sugar beet (Beta vulgaris L.) and cabbage (Brassica oleraceacapitataL.). Korean $J$. plant Res 7: 226-232.
17. Khodarahmpour Z, Imufar M, Motamedi M (2012) Effects of $\mathrm{NaCl}$ salinity on maize (Zea mays L.) at germination and early seedling stage. Afr. J. Biotechnol. 11: 298-304.

18. Rupela K (1999) Physiological response of plants to salinity. A review.Can. J. Plant Sci. 78:19-27.

19. Almansouri MJ, Kinet M, Lutts S (2001) Effect of salt and osmotic stress on germination in durum Wheat (Triticum durum Desf.) Plant Soil 231:243-254.

20. Morris B, Charles S, Son S (2003) Legumes In: Solomon HK (ed.) Encyclopedia of Food and Culture. New York.

21. Lewis G, Schrirer B, Mackinder B (2005) Legumes of the World: Royal Botanical Gardens. Kew, UK.

22. Graham PH, Vance Cp (2003) Legumes, importance and constraints to greater use. Plant physiol.131: 872-877.

23. Geressu K (2011) The Response of Some Haricot Bean (Phaseolus vulgaris) Varieties for Salt Stress during Germination and Seedling Stage. Curr Res. J. Biol. Sci. 3: 282-288.

24. Turan MA, Turkmen N, Taban N (2007) Effect of $\mathrm{NaCl}$ on stomatal resistance and proline, chlorophyll, $\mathrm{Na}, \mathrm{Cl}$ and $\mathrm{K}$ concentration of lentil plants. J. Agron. 6: 378-381.

25. Allen D J, M. Desert, S.C. Wortman (1999) Common bean in Africa and its constraints. Colombia, 1-32 P.

26. Saxena M (1990) Long term effect of soil salinity on chemical characteristics of soil. Indian soil. Pp.565-570.
Copyright: (C2020 Firew Admasu Hailu. This is an open-access article distributed under the terms of the Creative Commons Attribution License, which permits unrestricted use, distribution, and reproduction in anymedium, provided the original author and source are credited. 